\title{
Driving Regional Economic Models with a Statistical Model: Hypothesis Testing for Economic Impact Analysis
}

\author{
Stephan Weiler, John Loomis, Robby Richardson, and \\ Stephanie Shwiff*
}

\begin{abstract}
Policy models such as Input-Output (IO) or Computable General Equilibrium (CGE) are deterministic, with exogenous final demand shocks producing point estimates of local impacts. Confidence intervals around these point estimates, while desirable, are not readily available. Using the causal statistical model to form confidence intervals around the input/shock estimates allows for the configuration of confidence intervals around the output/impact results. The method is demonstrated on a sample policy scenario, which tests the relative significance of population versus climate change as a determinant of local economic activity in Rocky Mountain National Park's gateway community.
\end{abstract}

\section{INTRODUCTION}

Input-output (IO) and computable general equilibrium (CGE) models are widely useful tools for examining the potential impacts of hypothetical shocks to local economies. Yet the deterministic character of the resulting estimates can make the comparison of different scenarios difficult, since confidence intervals are not natural by-products of traditional input-output analysis. However, the use of forecasting models to estimate the scale of potential shocks, whether by regression or simple measures of central tendency, allows the construction of confidence intervals around the potential impacts of new final demands. These confidence intervals can increase the information content of IO analyses and their contribution toward making optimal resource allocation decisions (English 2000).

As noted by English (2000), there has been little empirical research on the variability of results in the economic impact literature. English (2000) suggests that variability in the impact analysis of a particular policy change can be usefully understood in two complementary parts. The first involves variability in the estimates of spending per unit (e.g., business, visitor, worker, or household), while the second assesses the variability in the estimation of the number of spending units likely to result. English (2000) uses a bootstrap technique to capture the inherent variability in the spending per unit, thus generating confidence intervals around the first type of estimate. As he notes, this is a time-consuming approach; his example took 120 hours over three weeks, as the IO model is re-run for every bootstrap sample.

The principal contribution of our paper is to provide a relatively simple method to construct confidence intervals around the change in the estimated total

*Weiler and Shwiff are from the Department of Economics, and Loomis and Richardson are from the Department of Agricultural and Resource Economics, Colorado State University, Fort Collins, Colo. 
number of spending units, such as new tourists in a local community. In this case, forecast regression models of exogenous shocks to a system are used not to pinpoint estimates of final demand, but rather to derive confidence intervals of the range of likely new final demands. These endpoints of final demand can be introduced into the IO analysis as upper and lower bounds of a hypothesized shock. The resultant endpoint impacts thus represent the likely range of local economic effects.

By combining statistical and deterministic approaches, this paper details and demonstrates a method that can provide useful confidence intervals for deterministic models. These explicit confidence intervals can then be used to compare a variety of scenarios and outcomes, providing researchers with a tool to assess the relative significance of different economic drivers. As an illustrative example of the types of comparisons the method makes possible, this paper contrasts the relative significance of climate change and population growth on local economic activity of a national park gateway community through park visitation.

\section{BACKGROUND AND THEORY}

\section{Motivation}

To forecast projected states of the future economy using an IO model requires estimating the exogenous factors that are likely to affect the local economy. Once these variables are estimated, the IO model calculates point estimates of the endogenous repercussions of the likely exogenous evolutions. However, such point estimates are not ideal comparative tools for evaluating competing policies, as there are no explicit confidence intervals to evaluate whether one scenario's impacts are significantly different from another.

Integrating regional IO structures with statistical models provides a potential framework within which the best qualities of both types of analysis can be captured. Exogenous inputs into IO models are often based on regression results that themselves have explicit stochastic elements. For example, the U.S. Forest Service makes projections of national forest timber supply and demand using an econometric model called TAMM (Adams and Haynes 1980).

Since one can construct confidence intervals for the outputs of the regressions that determine final demand, and these outputs are used in turn as inputs into the IO model, confidence intervals for IO impact outputs should then also be possible. Even when a regression model is not used, estimates of potential exogenous shocks are often constructed by taking averages of time series or cross section data. Such averages also have standard errors from which confidence intervals can be constructed. These confidence intervals can be used in a manner similar to that described for the regression approach. The endpoints of such confidence intervals can be introduced as the upper- and lower-bound exogenous final demand shocks into an IO analysis. The upper and lower bounds of resultant IO endogenous impacts create an effective confidence interval around the changes predicted by the IO model. It would then be possible to determine whether the 
impacts of different types of shocks, including those induced by policy, are significantly different given the underlying variability of the shocks themselves.

For example, one could use this technique to test the hypothesis that increasing government spending will have a statistically different effect on output from a parallel increase in household spending, based on estimates of future spending as a result of regression analysis. Given this basis, confidence intervals could be formed around the household spending estimates, creating an upper and lower bound for the exogenous final demands to be introduced into an IO model. Using the bounds of this confidence interval to drive the IO impact estimates of changes in exogenous spending on endogenous factors, it would then be possible to be "confident" within a certain degree as to whether increasing government spending has a statistically different impact on output from increasing household spending.

\section{Analytical Method}

The standard IO system can be written in matrix notation as

$$
\mathrm{Y}=(1-\mathrm{A}) \mathrm{X},
$$

with the solution structure of

$$
\mathrm{X}=(1-\mathrm{A})^{-1} \mathrm{Y} \text {. }
$$

$X$ is the vector of inputs, $Y$ is the vector of final demand variables, and $(I-A)^{-1}$ is the total requirements matrix. The elements in the $(\mathrm{I}-\mathrm{A})^{-1}$ matrix translate the given levels of final demand into the direct and indirect outputs from each sector of the economy required to satisfy this final demand. Using Equation 2, we may find the levels of output from all sectors required to support specified levels of final demand in all sectors. In addition, Equations 1 and 2 have dynamic representations of

$$
\Delta \mathrm{Y}=(1-\mathrm{A}) \Delta \mathrm{X} \text { and } \Delta \mathrm{X}=(1-\mathrm{A})^{-1} \Delta \mathrm{Y},
$$

respectively (Miller and Blair 1985).

The formula for calculating confidence intervals for final demand estimates $\mathrm{Y}$, either in levels or changes, based on econometric results is

$$
(1-\alpha) 100 \% \text { Confidence Interval }=Y \pm t_{\alpha / 2} \operatorname{se}\left[1+W^{\prime}\left(Z^{\prime} Z\right)^{-1} W\right]^{0.5} .
$$

A $95 \%$ confidence interval for this analysis is calculated using $t=2$; se represents the standard error of the regression. The $\mathrm{Z}$ matrix represents the explanatory exogenous variables, while the $\mathrm{W}$ matrix represents adjusted or future value of those variables in the generation of each of the forecasts. Thus, the matrix $\left[\mathrm{W}^{\prime}\left(\mathrm{Z}^{\prime} \mathrm{Z}\right)^{-1} \mathrm{~W}\right]$ represents the adjusted variables. In this paper's application, the adjusted variables reflect climate change scenarios and population forecasts. The new standard error for resulting final demand estimates $Y$ is therefore represented by se $\left[1+W^{\prime}\left(Z^{\prime} Z\right)^{-1} W\right]^{0.5}$ (Mendenhall, Wackerly, and Scheaffer 1990). 
Combining Equations 3 and 4 yields the impact calculation formula for the upper and lower bounds of the $95 \%$ confidence intervals for the resultant endogenous IO estimates. The upper bound can be written as

$$
X_{\mathrm{UB}}=(1-\mathrm{A})^{-1} *\left[\mathrm{Y}+\mathrm{t}_{\alpha / 2} \mathrm{se}\left[1+\mathrm{W}^{\prime}\left(\mathrm{Z}^{\prime} \mathrm{Z}\right)^{-1} \mathrm{~W}\right]^{0.5}\right]
$$

and the lower bound is expressed as

$$
X_{L B}=(1-A)^{-1} *\left[Y-t_{\alpha / 2} s e\left[1+W^{\prime}\left(Z^{\prime} Z\right)^{-1} W\right]^{0.5}\right] \text {. }
$$

The range of predicted final demand variables-in this case new visitor expenditures through $\mathrm{Y}$-will result in a range of necessary endogenous adjustments, such as increases in local retail output, which will be required to meet this new final demand. Equations 5 and 6 thus provide the link between the econometric model and the IO model. This link allows for the creation of confidence intervals around deterministic model estimates.

\section{ILLUSTRATIVE APPLICATION AND RESULTS}

We illustrate our technique by testing whether more certain future population increases or more uncertain climate changes would have significant effects on visitation to Rocky Mountain National Park (RMNP) and consequent employment in its gateway community of Estes Park, Colorado. Given their potential effects on local economic activity, population and climate change drivers provide a convenient illustrative example of hypothesis testing in a potential policy context.

Population growth along the Colorado Front Range is likely to be the principal factor in future RMNP visitation, with a considerably more certain impact than climate change. This paper focuses on climate and population drivers to influence visitation in RMNP, with visitor expenditures in turn being the major determinant of economic activity in the gateway community. The relative significance of these factors to the local economy is important for both local and broader RMNP policy and transportation planning. In order to simulate a useful planning horizon, the present effort focuses on projecting the 2020 climatic and population effects on visitation.

The population driver has been evolving significantly. Population in Estes Park and visitor use of RMNP have almost doubled since 1960. Current rates of human population change are 2 to 3 percent for many areas in the Rocky Mountains, with resulting urban sprawl and development in mountain communities (Stohlgren 1998). Even faster growth is occurring along the Colorado Front Range, which is the major source of potential RMNP visitors.

The analysis of the climate change driver focuses on the monthly and annual changes in precipitation and temperature due to higher levels of greenhouse gas (GHG) concentrations. These higher levels of GHG have been used to simulate changes in global climate. Results from two global circulation models (GCMs) are used to estimate potential climate changes for the Rocky Mountain Region, including RMNP and the Estes Park area. 
Both of the scenarios developed by the two models use 1961 to 1990 as the baseline for the assessment. The Canadian Climate Center (CCC) model scenario predicts monthly variation that ranges from $2.0^{\circ}$ to $2.8^{\circ} \mathrm{C}$ increases in peak-season maximum temperatures (with a mean increase of $2.4^{\circ} \mathrm{C}$ ), and $0.9^{\circ}$ to $3.8^{\circ} \mathrm{C}$ increases in off-peak season minimum temperatures (with a mean increase of $2.3^{\circ} \mathrm{C}$ ). CCC also predicts a drier overall climate. The Hadley model scenario predicts monthly variation that ranges from $-0.2^{\circ}$ to $2.0^{\circ} \mathrm{C}$ changes in peak-season maximum temperatures (with a mean increase of $1.0^{\circ} \mathrm{C}$ ), and $0.6^{\circ}$ to $2.5^{\circ} \mathrm{C}$ warmer off-peak season minimum temperatures (with a mean increase of $1.7^{\circ} \mathrm{C}$ ). Hadley tends to estimate a wetter winter or off-peak months and drier summer or peak months. While such predictions imply an acceleration of warming relative to recent history, the estimates are based on the increasing rate of greenhouse influences on climate. Many GCMs in fact project a $1^{\circ}$ to $2^{\circ} \mathrm{C}$ increase during the next 20 to 30 years (NAST 2001).

The proposed method of using the regression estimates to create confidence intervals around IO impacts will be used to test the hypothesis that the changes in Front Range population create the only statistically significant impact on the Estes Park area. To reject this hypothesis implies that climatic changes as predicted by the CCC and Hadley models also have a statistically significant impact on Estes Park, in addition to the effect of population increase.

\section{IO Model Specification}

IMPLAN is the most commonly used system available for IO and Social Accounting Matrix (SAM) modeling. A key issue is the spatial definition of the area of analysis, which in IMPLAN can range from state to county to zip code. Regions with smaller economic mass tend to face considerable leakages due to limited availability of local suppliers, and thus may be particularly dependent on export earnings for viability. Estes Park has such an economic orientation, characterized in this case by its dependence on tourist visitation. This type of economy typically has most sectors producing goods and services that are consumed directly by visitors to the economy rather than indirectly by other local industries. Visitation effects on the final demand sectors are thus felt primarily through increases in direct demand for particular industries' products, such as lodging and food. Induced effects through additional household income also tend to seep quickly out of the local economy, given a similar lack of local suppliers.

The choice of relevant spatial boundaries had to incorporate likely channels of ecological-to-economic activity, while recognizing the quality realities of sub-county data. The overlaps of the two concerns indicated that Zip Code level data ( 80511 and 80517 ) would be best suited for the local economy research, since natural changes will impact the local economy by visitors moving directly through Estes Park. The two zip codes are roughly accurate representations of the boundaries of local economic activity. The original IMPLAN zip code data was updated with several local, state, and national sources. The model was then calibrated to include local households and local government as endogenous sectors, 
which should reflect the effects of internal growth in such an economy. Visitors and their expenditures remain critical exogenous drivers.

Because visitor expenditure profiles do not exist for RMNP, visitor expenditure data was gathered from two other national parks chosen for their similarity to the present situation. Yosemite National Park was chosen because like RMNP it is situated near a large metro area; Yosemite total visitor per capita spending was thus used as a benchmark. Grand Teton National Park has a single major gateway playing a similar role to that of Estes Park to RMNP. This symmetry suggests that spending proportions for Grand Teton NP were likely to be broadly representative of expenditure shares of RMNP visitors in Estes Park. Of course, since the same expenditure levels are used for population and climate change scenarios, the exact level of expenditure will not affect our hypothesis test but would affect the levels of new/lost jobs forecasted. Note that since such expenditure estimates are often derived from multiple-sample averages, standard errors around these estimates could also be used to develop confidence intervals for impacts.

Using the combined data gathered from these two parks, we used an estimate of $\$ 68$ per visitor of local expenditures divided among six sectors: lodging (\$27), eating/drinking establishments (\$12), travel (\$11), equipment/miscellaneous retail (\$11), recreation services (\$4) and food stores (\$3). Direct impacts would occur in the six directly affected industries. The increase in activity in these industries would result in some indirect impacts on related supply industries, such as restaurant supply and wholesale trade/transportation. However, given the size of this community, many of these indirect effects would likely occur outside the local area, spilling towards the larger Front Range metropolitan economies. Induced impacts on households and local government would reflect the increased income (and thus spending) of households as well as greater needs for local government services. The combined direct, indirect, and induced effects produce the final changes in output, income, and employment for the local economy. For clarity of exposition, this paper focuses on employment impacts.

\section{Econometric Specification}

Ideally, we would like to have an equation that predicts the levels of final demand in response to climate and population. Lack of site-specific data on visitor spending requires us to determine final demand in two steps. In the first step, we estimate visitation as a function of climate and population. Then we apply the noted visitor expenditure profile to these visitation estimates in the second step to get changes in final demand.

We model total visitation to RMNP for month $i$ as a function of several climate and demographic variables. The econometric model takes the form

$$
\mathrm{V}_{\mathrm{i}}=\mathrm{X}_{\mathrm{i}} \beta \text {, }
$$

where $V_{i}$ represents total visitation for month $i, X_{i}$ represents the climate and demographic variables for month $i$, and $\beta$ represents the vector of parameters for each independent variable. The specified model takes the form 


$$
V_{i}=\beta_{0}+\beta_{1} S_{i}+\beta_{2} T_{i}+\beta_{3} P_{i}+\beta_{4} \text { Pop }_{i}+\beta_{5} \operatorname{SVDV}_{i}+\varepsilon_{i},
$$

where $S_{i}$ represents average snow depth for month $i, T_{i}$ represents average maximum temperature for month $i, P_{i}$ represents total precipitation for month $i, P_{i}$ represents average monthly population for 12 counties along Colorado's Front Range, $S V D V_{i}$ represents a dummy variable for school vacation months (for which SVDV $=1$ for July and August), and $\varepsilon_{\mathrm{i}}$ represents the normally distributed disturbance term.

Monthly visitation data were provided by RMNP administration for the years 1987-99. The Natural Resources Ecology Laboratory at Colorado State University provided climate data. Population data and projections for the Front Range counties of Colorado were gathered from the state demographer's office, and include Adams, Arapahoe, Boulder, Clear Creek, Denver, Douglas, El Paso, Gilpin, Jefferson, Larimer, Teller, and Weld counties.

Since monthly visitation at RMNP varies significantly throughout the year, reaching its peak during the summer months and dropping to its low during the winter months, the Chow test was performed to determine if the regression coefficients are structurally different in seasonal subsets of the data (Chow 1960). The F statistic for testing the restriction that the coefficients in the two seasonal regressions are the same is 22.32 . The critical value is 2.36 for $5 \%$ significance, so we rejected the hypothesis that the coefficient vectors are the same for the two seasons. Two subsets of observations were thus created to analyze the relationships for the peak (May-October) and off-peak (November-April) seasons (Greene 2000).

Consequently, two separate seasonal regression models of historic visitation data against explanatory climate and demographic variables for the period 1987-99 took the form

(9) Peak (May - Oct)

$$
\mathrm{V}_{\mathrm{i}}=\beta_{0}+\beta_{1} \mathrm{~S}_{\mathrm{i}}+\beta_{2} \mathrm{Tmax}_{\mathrm{i}}+\beta_{3} \mathrm{P}_{\mathrm{i}}+\beta_{4} \mathrm{Pop}_{\mathrm{i}}+\beta_{5} \mathrm{SVDV}_{\mathrm{i}}+\varepsilon_{\mathrm{i}}
$$

(10) Off - Peak (Nov - Apr) $V_{i}=\beta_{0}+\beta_{1} S_{i}+\beta_{2} T \min _{i}+\beta_{3} P_{i}+\beta_{4} P P_{i}+\varepsilon_{i}$,

where $T \max _{\mathrm{i}}$ represents average maximum temperature in month $\mathrm{i}$ for the peak season regression and $\mathrm{Tmin}_{\mathrm{i}}$ represents average minimum temperature in month $i$ for the off-peak season regression. The regression coefficients for the independent variables are provided in Table 1.

The regression coefficients display the expected signs. The coefficient on the snow depth variable is negative for the peak season regression and positive for the off-peak regression, which supports the recreation activities for each season. The opposite is true for the coefficient on the precipitation variable; more visitors during rainier summer months could be due to park re-entry following seasonal afternoon thunderstorms. The $\mathrm{R}^{2}$ is 0.88 for the peak season model and 0.31 for the off-peak model. The Durbin-Watson statistics are not significantly above 2.0 for either model, which suggests that we can accept the null hypothesis that there is no significant autocorrelation in the data 
TABLE 1

RMNP Visitation Regression Results

\begin{tabular}{|c|c|c|c|c|c|c|}
\hline \multirow{3}{*}{$\begin{array}{l}\text { Regression } \\
\text { Coefficients }\end{array}$} & \multicolumn{3}{|c|}{ Peak (May-October) } & \multicolumn{3}{|c|}{ Off-Peak (November-April) } \\
\hline & & Std. & $t-$ & & Std. & \\
\hline & Value & Error & Statistic & Value & Error & Statistic \\
\hline Intercept $\left(\beta_{0}\right)$ & $-639,549.7$ & $162,598.1$ & -3.9333 & $23,247.2$ & $18,155.8$ & 1.2804 \\
\hline Snow Depth $\left(\beta_{1}\right)$ & -386.3 & 71.0 & -5.4388 & 17.5 & 8.5 & 2.0513 \\
\hline Max. Temp. $\left(\beta_{2}\right)$ & $18,457.7$ & $3,330.1$ & 5.5427 & n.a. & n.a. & n.a. \\
\hline Min. Temp. $\left(\beta_{2}\right)$ & n.a. & n.a. & n.a. & $1,257.2$ & 413.4 & 3.0410 \\
\hline Precipitation $\left(\bar{\beta}_{3}\right)$ & 846.4 & 302.9 & 2.7947 & -60.4 & -1.3 & -1.2603 \\
\hline Front Range Pop. $\left(\boldsymbol{\beta}_{4}\right)$ & 0.216 & 0.050 & 4.3088 & 0.016 & 2.5 & 2.4907 \\
\hline School Vac. DV $\left(\beta_{5}\right)$ & $200,961.4$ & $27,049.0$ & 7.4295 & n.a. & n.a. & n.a. \\
\hline & 0.8840 & & & 0.3064 & & \\
\hline Adjusted $R^{2}$ & 0.8741 & & & 0.2624 & & \\
\hline Durbin-Watson Stat. & 2.4566 & & & 2.1986 & & \\
\hline
\end{tabular}

\section{Confidence Intervals for IO Models}

In order to compare the confidence intervals of the forecasts of future monthly visitation under the No Climate Change, CCC, and Hadley scenarios, we generated two baselines and seven forecasts of monthly visitation, then used the associated standard errors to estimate confidence intervals based on the model presented in section 2. For the peak season, visitation was estimated for baseline 1996 population with and without CCC Climate Change, then for 2020 population under the No Climate Change, CCC, and Hadley scenarios. This visitation forecast was derived by multiplying the scenarios' temperature, precipitation, snow depth, and population levels by their respective coefficients from the regression equation. Off-peak season visitation was estimated for 2020 population under the same three ensuing climate scenarios; as will be evident from Figure 1, a CCC Climate Change Only scenario was unnecessary. The results are provided in Table 2.

TABLE 2

Forecasted Future Visitation to RMNP

\begin{tabular}{|c|c|c|c|c|c|c|}
\hline \multirow[b]{2}{*}{ Regression Models } & \multirow{2}{*}{$\begin{array}{c}\text { Mean } \\
\text { Monthly } \\
\text { Visitation }\end{array}$} & \multirow{2}{*}{$\begin{array}{c}\text { Total } \\
\text { Season } \\
\text { Visitation }\end{array}$} & \multirow{2}{*}{$\begin{array}{l}\text { Monthly } \\
\text { Standard } \\
\text { Error }\end{array}$} & \multicolumn{3}{|c|}{ 95\% Confidence Intervals } \\
\hline & & & & Minimum & Maximum & Width \\
\hline Peak (May-Oct): & & & & & & \\
\hline 1996 B & 422,717 & $2,536,303$ & 71,808 & $1,674,612$ & $3,397,993$ & $1,723,380$ \\
\hline 1996 Pc & 478,807 & $2,872,839$ & & 1,99 & & 1,7 \\
\hline No Climate Change & 814,234 & $4,885,404$ & 116,1 & 3,49 & & $2,7 \varepsilon$ \\
\hline 2020 Pop. 8 & 870,324 & $5,221,941$ & 117,683 & 3,809 & 6,63 & $2,824,382$ \\
\hline 2020 Pop. \& Hadley & 846,285 & $5,077,711$ & 116,583 & $3,678,710$ & $6,476,711$ & $2,798,002$ \\
\hline Iff-Peak ( & & & & & & \\
\hline 1996 Baseli & 64,096 & 384,574 & 9,608 & 269,278 & & 230,592 \\
\hline 2020 Pop. \& No Climate Change & 93,730 & 562,383 & 15,338 & 378,332 & 746,434 & 368,101 \\
\hline 2020 Pop. \& CCC & 94,261 & 565,564 & 15,531 & 379,189 & 751,938 & 372,749 \\
\hline 2020 Pop. \& Hadley & 95,089 & 570,534 & 15,478 & 384,792 & 756,276 & 371,484 \\
\hline
\end{tabular}

The estimated peak season visitation with climate change under both the CCC and Hadley scenarios is higher than the no climate change scenario, indicating the effects of reduced snow depth, higher maximum temperatures, and in the case 
of the Hadley model, more precipitation. Overall, peak season visitation is forecasted to be higher if future climate follows CCC model projections due to its higher temperature estimates (most evident in May, June, July, and October). The estimated off-peak visitation is generally estimated to be greater than that of the historic period, illustrating the effects of greater snow depth and higher minimum temperatures. The key question, however, still involves ascertaining the relative significance of population versus climate change effects.

Clearly, for both seasonal regressions, the standard errors for the 2020 forecasts are significantly greater than that for the original regression analysis and, in both cases, the related confidence intervals are approximately 1.6 times that of the original regression analysis. The confidence intervals for the 2020 forecasts under the CCC and Hadley climate change scenarios are slightly greater than that for the no climate change forecast, reflecting the increased variability in the climate variables under climate change scenarios. The CCC scenario appears to have greater variability than the Hadley scenario.

The construction of confidence intervals around the visitation estimates, which are the basis for final demand inputs into the IO model, implies that confidence intervals can now be constructed around the resulting IO estimates of endogenous output and employment impacts. IO models imply constant employmentto-output ratios; output demand findings thus easily translate into jobs. As policy makers often prefer more intuitive employment levels to portray impacts, we use this measure for expository purposes as well.

Given that the regression estimates on visitation had $95 \%$ confidence intervals constructed around them, upper and lower bounds of the visitation confidence interval represent the highest and lowest predicted levels of economic stimulus due to visitor spending. Incorporating these visitation bounds into the IMPLAN model can thus create estimates around job impacts with the same $95 \%$ confidence interval. In other words, the $95 \%$ confidence interval surrounding estimates of visitor spending as exogenous final demand inputs for the IO model allows for the construction of the same size confidence interval around the output and job impacts produced by the model. The Appendix details all visitation and employment effects of the various scenarios.

\section{Peak Months}

During the peak months of May through October, the baseline 1996 regression results from Table 2 estimated that mean monthly visitation as 422,717 with a standard error of 71,808 ; the mean total seasonal visitation was estimated to be $2,536,303$. Using the method noted above, the confidence interval formed around this total seasonal visitation estimate was at the minimum 1,674,612 (the lower bound of the confidence interval) and at the maximum 3,397,993 (the upper bound of the confidence interval).

We then introduced these visitors along with their postulated spending into the IMPLAN model to determine the local impact of baseline climate and 
population on employment for the 1996 baseline year. The mean total seasonal visitation was used to determine the mean number of jobs $(6,266)$ that would result from the $2,536,303$ visitors in the peak season. The upper $(3,397,993)$ and lower $(1,674,612)$ bounds of the visitation confidence interval surrounding the mean were then entered into IMPLAN to determine that there was $95 \%$ confidence that 6,266 jobs plus or minus 2,129 jobs would be created in the baseline peak season as a result of visitation.

The first issue is whether climate change alone has a statistically discernible effect on the baseline results. Given that both climate models project distinctive climate effects in peak periods and that CCC predicts the greatest climate change, we focus on the peak season and a CCC-only scenario for our initial contrast. We superimposed the CCC climate scenario on the baseline population, which yielded with $95 \%$ confidence a range of 2,157 jobs above and below the mean of 7,097 . Figure 1 directly contrasts the baseline situation with the baseline plus CCC climate change scenario. Given that the two confidence intervals clearly overlap, we can assert that climate change alone does not seem to have a statistically significant impact on the Estes Park economy relative to the baseline. Given the more muted effects of climate on visitation and thus job impacts during the off-peak period, the lack of climate effects during the peak season implies a similar lack of effects for the off-peak period, which (although not shown) is indeed the case.

FIGURE 1

Peak Season Baseline Jobs With and Without Climate Change

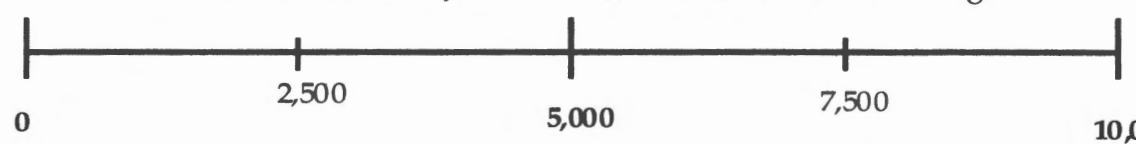

10,000

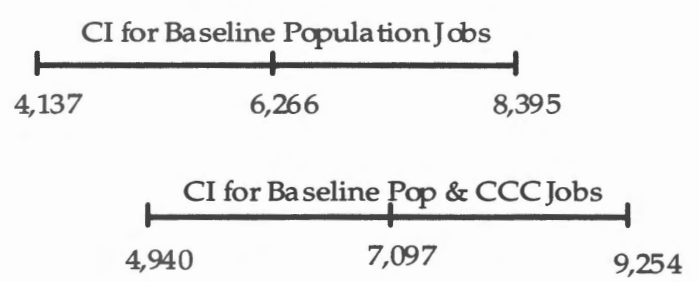

The 2020 comparison of population and climate change effects required progressive estimation of the two impacts in isolation as well as in combination, since interactions between the two effects are also possible. The regression coefficients were first used to extrapolate the impact of population alone on visitation under the No Climate Change scenario. Mean monthly visitation was estimated to be 814,234 , with a standard error of 116,155 , resulting in a mean total seasonal visitation of $4,885,404$. Using the same method as noted above for the baseline example, this information was used to construct a confidence interval around the mean total seasonal visitation results. The maximum or upper bound was estimated to be $6,279,263$ and the minimum or lower bound was $3,491,545$, or the mean plus or minus $1,393,859$. The new visitors would result in a mean of 12,070 jobs plus or minus 3,444 . 
Similar procedures were used to create confidence intervals around the regression results combining population change with the two climate (CCC and Hadley) models. The CCC model in combination with population growth estimated that mean total seasonal visitation would be $5,221,941$, plus or minus $1,412,191$ in 2020. From this visitation estimate, the mean number of jobs in 2020 under the CCC scenario would be 12,901 plus or minus 3,489 . When the Hadley model and population estimates were combined, the estimate for mean total seasonal 2020 visitation was $5,077,711$ plus or minus $1,399,001$. This translated into 12,545 jobs in 2020 plus or minus 3,456.

As can be seen from Figure 2 for the peak season, the confidence intervals for 1996 baseline jobs and 2020 population jobs do not overlap, signifying that they are statistically different from one another. Therefore, Front Range population growth between the two periods is expected to have a significant effect on visitation, local economic activity, and jobs in Estes Park. Note that this Front Range population growth proved to be the only significant difference in the 2020 peak season forecast. The confidence intervals for 2020 population jobs and the CCC and Hadley scenarios do overlap, implying that the changes in jobs due to population and both climate scenarios were statistically indistinguishable from those due to population alone. These examples underline the importance of the confidence intervals in assessing relative significance of different drivers of economic activity.

\section{FIGURE 2}

Peak Season Jobs With and Without Population and Climate Change

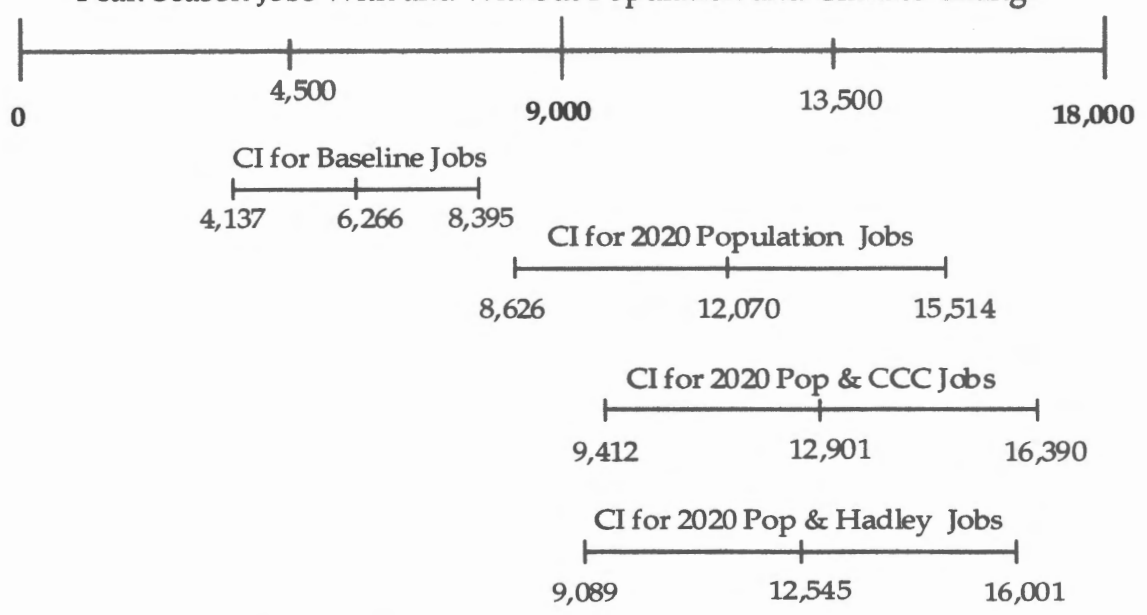

Given the results for the peak months, we accept the hypothesis that the only significant factor in determining future peak-season job creation was human population growth in the Colorado Front Range. This example underlines Colorado Front Range population as the most influential factor in the future number of peak-season jobs in the Estes Park area. Climate change effects are relatively minor, unless there are some nonlinear threshold effects associated with climateinduced visitation. 


\section{Off-Peak Months}

Due to the structural differences between visitation patterns in peak and off-peak seasons, results for off-peak months could be different. The Estes Park economy is driven mainly by peak season visitation, due to its mountainous climate and the pattern of vacationers. In off-peak winter months, visitation to RMNP slows due to difficult winter driving conditions and the narrower interests of winter visitors. In fact, many businesses in Estes Park close down for several months during the off-peak season.

During the off-peak months of November through April, the 1996 baseline regression results estimated mean monthly visitation as 64,096 with a standard error of 9,608 . From this, the mean total seasonal visitation was estimated to be 384,574 . The confidence interval formed around this total seasonal visitation estimate was at the minimum 269,278 (the lower bound of the confidence interval) and at the maximum 499,871 (the upper bound of the confidence interval). Entering visitation's mean and bounds into the IO model provided a mean estimate and predicted range of resultant jobs. The mean total seasonal visitation was used to determine the mean number of jobs (950) that would result from the 384,574 visitors in the off-peak season. The upper $(499,871)$ and lower $(269,278)$ bounds of the confidence interval suggested with $95 \%$ confidence that 950 jobs plus or minus 285 jobs would exist in the baseline off-peak season as a result of visitation.

As in the peak months, the critical portion of the analysis was to determine whether increases in Front Range population and/or climate change scenarios had distinguishable economic impacts. As noted above, the pure climate effects on the baseline were statistically indistinguishable for both peak and off-peak periods. However, population change alone was shown to have a significant impact during the peak season, and could have similar effects in the off-peak scenario. Furthermore, interactions between population and climate change scenarios further require an evaluation of combined impacts.

In order to assess pure population effects from the baseline year regression results, the visitation estimate was calculated using 2020 information on population only, leaving all climate variable unchanged. Mean monthly visitation was estimated to be 93,730 , with a standard error of 15,338 , and a mean total seasonal visitation of 562,383. Visitation's maximum or upper bound was estimated to be 746,434 and the minimum or lower bound was 378,332 , or the mean plus or minus 184,051 . These visitors generate a mean of 1,389 jobs plus or minus 455 .

Similar procedures were used to create confidence intervals around the regression results of population change and the CCC and Hadley models. A CCC climate in combination with population growth resulted in mean total seasonal visitation of 565,564 , plus or minus 186,374 in 2020 . The mean number of jobs in 2020 based on this CCC forecast was 1,397 plus or minus 460 . When the Hadley model and population estimates were combined, the estimate for mean total seasonal 2020 visitation was 570,534 , plus or minus 185,742 . This translated into 1,410 jobs in 2020, plus or minus 459 . 
For the off-peak months, Front Range population growth and the climate changes predicted by the two models proved to be statistically the same as the baseline, again underlining the utility of this paper's confidence interval approach. As can be seen from Figure 3, the confidence intervals for 1996 baseline jobs and 2020 population jobs overlap, signifying that they are statistically identical to one another. The confidence intervals for 2020 population jobs and the CCC and Hadley scenarios also overlap, implying that the climate changes also do not provide a statistically distinguishable effect on jobs. The more local nature of winter visitation and the greater randomness of such flexible visits are likely much of the reason for these results.

FIGURE 3
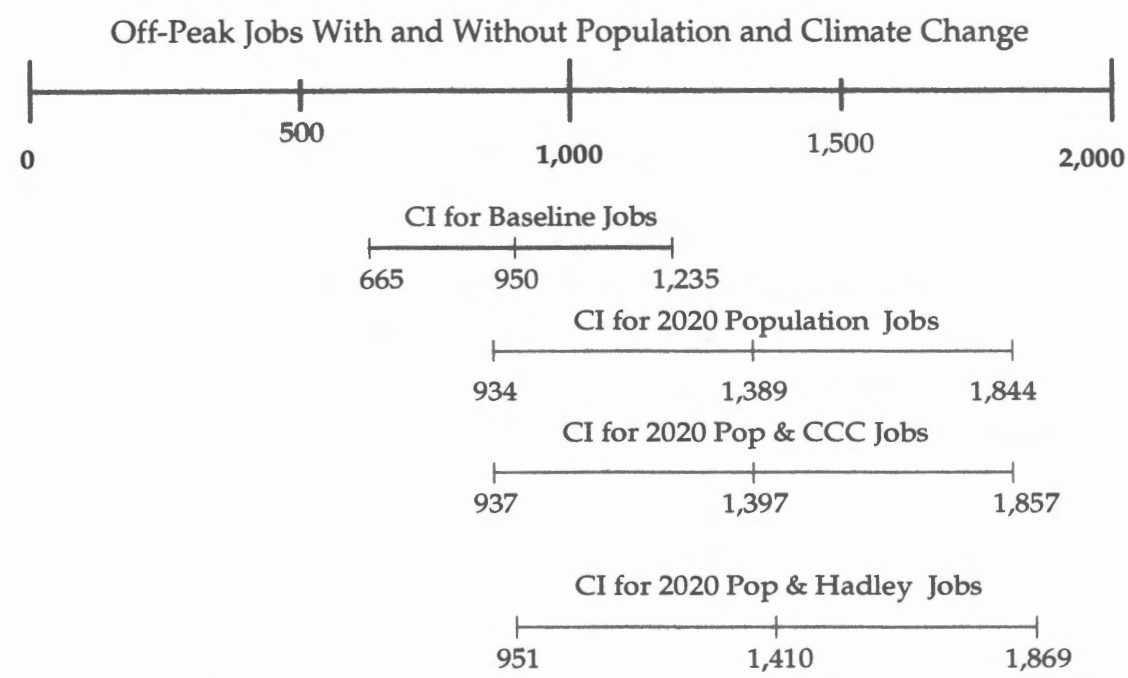

Given the results for the off-peak months, we rejected the hypothesis that either population growth or climate change had significant impacts on visitation and local economic activity during the winter season. This example again shows the potential utility of the method in comparing the impact of varying economic scenarios. Variations in off-peak climate or population are not likely to have substantial impacts on local jobs, and can therefore be lower priorities for contingency planning.

\section{CONCLUSION}

This paper has illustrated techniques to improve the comparability of policy model predictions by constructing confidence intervals around deterministic model estimates. This paper's method takes advantage of situations where statistical models or time series/cross section averages provide the inputs into predictive IO models. Given that averages of single variables or forecasts from a regression model have identifiable confidence intervals that can be introduced as the upperand lower-bounds of exogenous drivers, IO analytical results can then feature a range of predicted impacts based on confidence parameters.

In the illustrative case study example of the visitor-driven Estes Park economy, this technique is used to identify which factors played the most important 
role in the determination of local employment in 2020. Through the use of confidence intervals, the method indicates that peak season employment was likely to be significantly affected by Front Range population growth. At the same time, the analysis suggests that climate change projected by two different models would not significantly impact peak season jobs. In the off-peak months, neither population nor projected climate visitation drivers had statistically distinctive effects on future jobs.

The technique could be useful in planning situations, which generally require contrasts of alternatives. Traditional IO models with their deterministic estimates make such comparisons difficult. Different alternatives that seem to result in distinguishable effects on the economy may in fact be statistically indistinguishable. IO models supplemented by the confidence interval technique can facilitate meaningful comparisons between alternatives, improving both applicability and credibility of estimates (Loomis, Creel, and Park 1991).

Future research should explore the development of joint confidence regions that reflect both the variability in spending per unit, as in English's (2000) bootstrapping, as well as the variability in the estimated number of spending units, as in the approach described by this paper. Such a synthesis may be warranted for especially important policy analyses where large numbers of jobs and substantial regional income are at risk.

\section{APPENDIX}

Confidence Interval Results from Regression Analysis and IMPLAN Model

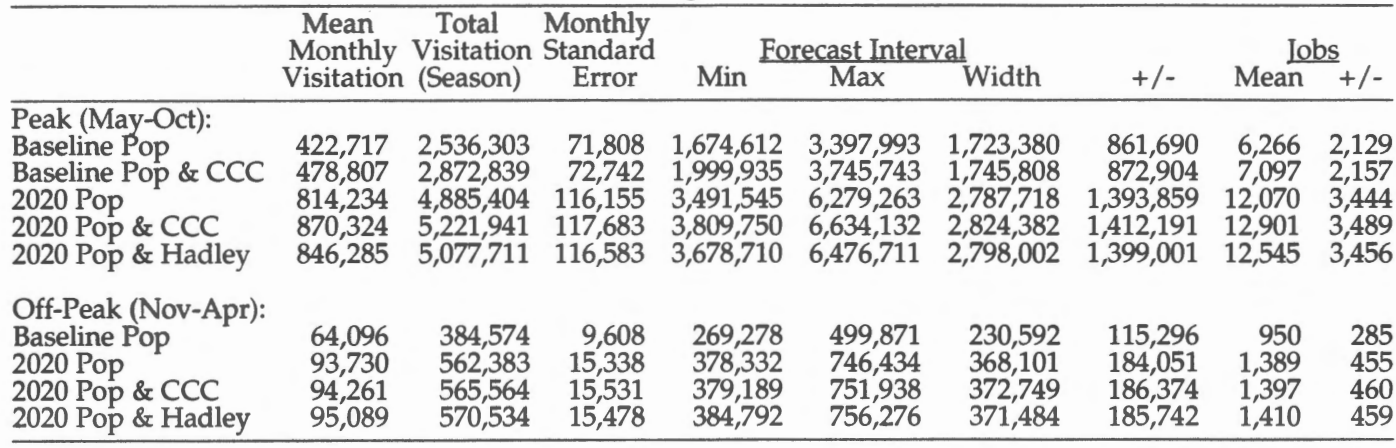

\section{REFERENCES}

Adams, D., and R. Haynes. The 1980 Softwood Timber Assessment Market Model: Structure, Projections, and Policy Simulations. U.S. Forest Science Monograph, no. 22. Washington, D.C.: Society of American Foresters, 1980.

Chow, G.C. "Tests of Equality between Sets of Coefficients in Two Linear Regressions." Econometrica 28 (3) (1960), 591-605.

English, D.B.K. "Calculating Confidence Intervals for Regional Economic Impacts of Recreation by Bootstrapping Visitor Expenditures." Journal of Regional Science 40 (3) (2000), 523-539.

Greene, W.H. Econometric Analysis. Upper Saddle River, N.J.: Prentice Hall, 2000. 
Loomis, J., M. Creel, and T. Park. "Comparing Benefit Estimates from Travel Cost and Contingent Valuation Using Confidence Intervals for Hicksian Welfare Measures." Applied Economics 23 (1991), 1725-1731.

Mendenhall, W., D.D. Wackerly, and R.L. Scheaffer. Mathematical Statistics with Applications. Boston: PWS-KENT Publishing Company, 1990.

Miller, R.E., and P.D. Blair. Input-Output Analysis Foundations and Extensions. Englewood Cliffs, N.J.: Prentice-Hall, 1985.

National Assessment Synthesis Team (NAST). Climate Change Impacts on the United States: The Potential Consequences of Climate Variability and Change. Cambridge, UK: Cambridge University Press, 2001.

Stohlgren, T.J. "The Rocky Mountains." In M.J. Mac, P.A. Opler, C.E. Puckett Haecker, and P.D. Doran (eds.) Status and Trends of the Nation's Biological Resources. Vol. 2, 473-504. Reston, Va.: U.S. Department of the Interior, U.S. Geological Survey, 1998. 
